\title{
Literature stance in developing critical thinking: A pedagogical look
}

Khatib, Mohammad

Assistant Professor, Allameh Tabataba'i University, Tehran, Iran (mkhatib27@yahoo.com)

Shakouri, Nima

Islamic Azad University, Science and Research Branch, Tehran, Iran (nima.shakouri2011@gmail.com)

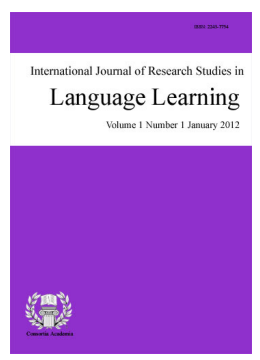

ISSN: 2243-7754 Online ISSN: 2243-7762

OPEN ACCESS

\section{Abstract}

Students in literature classes are expected to think critically and apply their critical and analytical skills to the texts they study. As to the writers, the factors counted by some scholars (e.g. Topping, 1968) as the demerits of the employment of literature in EFL/ESL classes including difficulty level of vocabulary, structural complexity, non-normative use of language, and even remote cultural perspectives are neither persuasive nor logical, but are exactly what can be employed to enrich language learning experiences, and enhance critical thinking. In any way, although providing students with tools of critical thinking, and more importantly, stabilize the stance of literature in its proper position is difficult, it is not far-fetched. The study was an attempt to investigate the efficacy of developing critical thinking through literature reading.

Keywords: literature; critical thinking; critical pedagogy; Socratic question; imagination 


\section{Literature stance in developing critical thinking: A pedagogical look}

\section{Introduction}

Ernst von Glasersfeld (1995), the so-called father of constructivism, cited in Williams and Burden (1997), believes that education has two main purposes: (1) to empower learners to think for themselves, and (2) to promote in the next generation ways of thinking and acting that are deemed important by the present generation. Put another way, education is not merely getting information or knowledge, but mainly causing a change in one's beliefs system. This cannot be obtained if the sender and receiver of information are demarcated. That is, the teaching is not done with the help of a linear sequence of events - with the teacher as primary as well as secondary actor and the student as silent audience. Pedagogically, students are not viewed as passive sponges waiting to soak up facts, or as metaphor receptacles that must be poured in and teachers in this model are not viewed as jars of which duties are to fill up these mugs. However, in most reading classes centered on, EAP teachers tend to focus on interpreting the meaning of a text, acting as 'arbiters of meaning' (Wilson, 2007, p. 367). Wilson also adds "the focus is often on completing comprehension exercises, rather than on engaging students in dialogue with texts" (p. 367). Such teachers claim because of the complexity of literary texts and lack of imagination power on students, arbitrating meaning of the text is becoming a constant and is an inevitable part of their duty; thus, to get rid of this problem, some teachers appeal to simplified texts. Still, such texts have their own demerits.

As Honeyfield (1977) holds simplification tends to produce a homogenized product in which the information becomes diluted. Moreover, employing additional words in text not only spreads the information but also adds the complexity of texts. Accordingly, Chastain (1988) claims syntactic simplicity may decrease text cohesion and hinder comprehension. As to reading specialists, simplifying texts reduces their natural redundancy and makes them more difficult to read (Chastain, 1988). Thus, according to Honeyfield (1977), what teachers should seek for is those texts the information of which is localized. Elsewhere, Honeyfield (1977) claims since proficient readers highly rest on cohesive devises and localized information, deleting these elements little help the readers; and decreases the readability of texts.

The philosophy behind simplifying texts is that students are expected to find meaning within the lines of words. However, meaning is not something static in the text but it is the result of interaction between what is in the text and readers' background knowledge. The interaction between the reader and the writer will lead students to internalize what they have read (Spack, 1985). This is an eloquent reference to Lev Vygotsky's (1981, cited in Wertsch, 2002, p. 106) socio-cultural theory that claims learning takes place on two planes: first through dialogue (intermental dialogue) and then within our own minds (intramental dialogue). Internalizing allows us to take ownership of ideas, to construct our own understanding of them for ourselves in ways which make sense to us as readers with our own individual histories, interests, and purposes. But it is only when we can externalize these constructed ideas, through speaking or writing about them, which offers a lens for better understanding. Along the same line it can be implied that literature cannot be taught as "a way of exploring, understanding and reflecting on the strategies by which readers...generate meanings in the act of reading" (Salvatori, 1983, cited in Spack, 1985, p. 709). In fact, as Rubinstein (1967, cited in Spack, 1985) argues writing is "not only a record of understanding, but an act of understanding” (p. 709).

\section{Critical Thinking: Why literature}

Once was literature the main source of input in language classes. During pre-scientific era the main source of input was literature. However, with the emergence of scientific era which was together with the decline of grammar-translation methods, literature has been dropped down the pedestal. The audilingual method which was the representative of this era paid more attention to dialogue and literature was stuck to the margin. According to 
Maley (2001), the emergence of such attitudes in literature is due to a paucity of empirical research. In the same line Malley puts, what exists right now as empirical research and language teaching are confined to action research in small scales.

Taking heed of all these disfavours, in the middle of the 1980s some practitioners and language scholars resurrected literature as a language learning material after a long period of being neglected (Duff \& Maley, 1991, cited in Khatib, Rezaei, \& Derakhshan, 2011, p. 201). Today, it goes without saying literature is the main source of critical thinking enhancement. The changes that it can bring in an individual's beliefs system is taken for granted. Literature, as Khatib et al. (2011) insist, is fertile with ideas to critically look at. Elsewhere, considering literature as a tool to develop critical thinking, they hold "Today, critical thinking is the cornerstone of education particularly at advanced levels of education" (p. 203).

To put frankly, literature reading is eminently congenial to the essential traits of critical thinking (Tung \& Chang, 2009, p. 291). Accordingly, Tung and Chang (2009) count two reasons in support of the issue that literature reading and critical thinking are emanated from the same origin. First, the mental process of literature reading requires critical thinking skills such as recalling, retrieving, and reflecting on prior experiences to construct meaning of the texts. While doing this, the readers are required to demonstrate the following capacities: to differentiate facts from opinions, to understand the literal or implied meanings to locate the details related to the issues discussed, to find out the causal relationships; to detect the inferential relationship from the details observed; to be perceptive of multiple points of views; to make moral reasoning and fair-grounded judgments; and apply what is learned to the real world. All these abilities, while reading, are considered to comprise critical thinking. Second, the subject matter, the setting and the language of a literary work provides readers with a variety of real-world scenarios to construct meanings of self and life incrementally. A piece of literature is a mirror of life and a world reconstructed. By investigating into its plot, thematic development, and the interactions of the characters with others and milieu, readers are exposed to multiple points of view and thus compelled to think and rethink their own ideas and actions. In the same line regarding the benefits of literature, Ellison (2010) claims there are five pedagogic reasons why literature should be used in the foreign language classroom:

$>$ Attitudinal: developing positive attitudes to language learning, different cultures, self and others;

$>$ Linguistic: natural exposure to the foreign language in context, lexis, grammar, discourse and pronunciation through patterns and repetitions in the narrative;

$>\quad$ Cultural and Intercultural: access to, and awareness and understanding of other cultures;

$>$ Social and Moral: emotional development/consciousness, empathy, shared experiences; and

$>$ Cognitive and Creative: use of the imagination and thought processes, academic skills development to support other learning (p. 22).

Also in similar vein, Fisher (1999) states there are strong pedagogical reasons for developing thinking skills in children through the use of literature. Fisher (1999) in a comparison between more able, literate children with less able ones concludes that successful learners have:

$>\quad$ Knowledge of literary forms, purposes and genre, including meta-linguistic knowledge;

$>\quad$ Skills and strategies for processing literary knowledge, including the ability to question, interrogate and discuss narrative texts; and

$>\quad$ Ability to apply and transfer their learning and knowledge to other contexts (cited in Elison, 2010, p. 24).

Gajdusek (1988, as cited in Bagherkazemi \& Alemi, 2010, pp. 2-3) also states though literature is both 
Khatib, M. \& Shakouri, N.

literally and figuratively de-contextualized, the context-reduced nature of literature entails internal coherence and conscious patterning which are considered as a perfect means for developing communicative competence in learners. That literature is internally coherent connotes that each line has an interrelation with other lines and that literature posses conscious patterning refers to the recurring patterns of sounds, meanings and structures that connect intellectual, emotional and physical experiences. Discovering, exploring and appreciating these patterns would create a lot of reader-text interaction which is an essential feature of communicative and interactional competence whose effect on individual critical thinking id undisputable.

\section{Critical thinking requires disposition}

Although developing Critical Thinking skills among students has been set as a primary goal in education for decades, Critical Thinking requires a critical person to have both the capacity and the disposition to seek reasons, truth and evidence. Dispositions, unlike skills, cannot be taught; they can only be cultivated through such activities as modeling (Reece, 2002). Furthermore, Critical Thinking is dependent upon a person's disposition to use it (Paul, 1983). Disposition to think critically can be defined as consistent willingness, motivation, inclination and an intention to be engaged in Critical Thinking while reflecting on significant issues, making decisions and solving problems (Facione, Sanchez, Facione, \& Gainen, 1995). According to Zoller, Ben-Chaim, and Ron (2000), a student's disposition to think critically is a necessary pre-condition for Critical Thinking and greatly affects Critical Thinking capability. Thus, the first and one of the most pivotal stipulation to pave the way and make students ready for critical thinking is to consider their needs in general and their disposition and interest in detail. However, it must not be done at the expense of destroying literature.

Lines can be written about the stance of literature in EFL context, but what is not plausible is that for making literature understandable and enjoyable, students must be made interested in reading. Accordingly, Chastain (1988) holds no reading takes place if one is not willing to continue reading. However trying to satisfy all the students is impossible as people are individual. Nevertheless, teachers can take some steps to improve current practices: (1) They can choose reading with which students have some familiarity; (2) They can use some pre-reading activities to generate interest.

Accepting literature as a source of pleasure is undeniable, but the choice of literature that meets students' linguistic and cultural need is not that much accessible that can be put into theory and practice in the class. Hence, as Bradford (1968) puts the lack of success will lead us to answer this question that "what is the nature of enjoyment derived from reading literature?" No teachers can instill a sense of enjoyment into students; in fact, literary enjoyment is not achieved through instruction. Furthermore, making literature enjoyable must not be at the expense of losing its critical power and significance. It is nonsensical to command a reader to enjoy a story. Enjoyment is beyond conscious control.

As Bradford (1968) claims enjoyment will be obtained as a result of literary experience. Elsewhere, he puts all literary experiences share certain characteristics: (1) The reader cannot consciously induce a literary experience; it must happen; (2) Literary experience requires a story suitable for the reader and a reader is willing to react to the story; and (3) Literary experience requires the readers' total intellectual and emotional involvement. Along the same line, Arthur (1968, cited in Bagherkazemi \& Alemi, 2010, p. 7) maintains, literary experience is an unconscious state of total intellectual and emotional engagement which must be regarded, not as a by-product of, rather as a prerequisite to using literature in the language classroom. This state is what is referred to as "psychological flow", a concept which has found its way to applied linguistics from the psychology of task performance. Interestingly, there is also research suggesting that flow is both a state and a trait. That is, it may be a state of mind and an experience, but there are also some people who are, by dint of their very special makeup, more susceptible to falling into that delicious state of flow. In fact, as to Strevens (2003), 'flow' which is characterized by heightened mental processes is the characteristic of successful language learners. 


\section{Developing the culture of thinking}

We all know that pleasure that literature can bring to EFL classes and the potential it has in the teaching process are undisputable. Literature can provide a strong tool to motivate students to think critically. If teachers go beyond simple recall of events, they can certainly influence student power of thinking. In effect, teaching students to think critically must include motivating them to come to their own conclusions. Implicitly, it is an obligation for a teacher to scaffold students in order that they he/she can provide an effective program for developing Critical Thinking which creates a culture of thinking in the classroom. To do that, (1) teachers' program should provide models of good reasoning behavior. The purpose of the models criterion is to make sure that students are provided with exemplars of what thinking dispositions look like in practice; (2) the program should also provide direct explanations about the purpose, concepts and methods of good reasoning. In other words, students should be told why good reasoning is important, and directly taught some key reasoning concepts and moves; (3) a program for teaching reasoning should provide plenty of opportunity for peer interaction around reasoning. These are interactions in which students reason together, discuss reasoning with one another, and evaluate reasoning together, and so on. The purpose of this criterion is to bring the thinking disposition alive for the student by anchoring it in meaningful interpersonal interactions; and (4) last but certainly not least, the program should provide plenty of opportunities for formal and informal feedback around thinking dispositions. Through teacher feedback, peer feedback, and self feedback, students should learn about the strengths and weakness of their reasoning behavior. Furthermore, students must be brought to criticality, and this can only be done by alerting them to the social conditions that have brought this about. In short, we can restate the problem as follows: Critical Thinking's claim is, at heart, to teach how to think critically.

\section{Scaffolding students to think: Critical pedagogy}

For students to be encouraged to think, teachers also have to think! To develop the culture of thinking, teachers must dare to come out of their traditional shells. Pedagogically, the very basic and fundamental culture of critical thinking is emanated from the sharp and meticulous distinction which is made between the banking system of education and the problem-posing education, proposed by Paulo Freire (cited in Monchiski, 2008). Accordingly, the banking system of education sees students as empty vessels waiting to be filled with information by knowledgeable teachers. This system of education is a mechanistic conception of education. It fits well with the assumptions of behaviorist learning theories (Monchinski, 2008.)

The two main characteristics of banking system of education could be defined as that the teacher knows everything and the student knows nothing and the teacher talks and the students listen. In fact, in such classes, a culture of silence exists. In these classrooms students feel what they say isn't or won't be considered important. This may lead to the "mutism" where students in classrooms avoid dialogue in favor of becoming silent. Mutism and a culture of silence signify oppression and dehumanization in classrooms. In fact, considering literature as a powerful tool to develop critical thinking in such contexts is totally ignored.

On the other hand, as direct opposition to the banking system of education, problem posing education as one form of the realization of critical pedagogy in classroom context encourages critical thinking. One of the teachers' roles in a problem-posing education is to "problematize situations" by presenting to students situations with which they are familiar but in a way that make them thinking about those situations in new ways. In effect, what makes a student in banking system distinct from the latter, problem-posing education is that in the banking system what is presented is a set of facts and students are simply the consumers of these facts, but in a problem posing system reading involve answering how a text portrays the subject matter. In doing so, a relationship is developed between an author and a reader with text as their meeting point of reference. Accordingly, Paulo Freire asserts,

A problem-posing view of education sees the identification and analysis of problematic aspects of reality as central to the curriculum. The teacher's role is not to transmit knowledge, but to 
engage students in their own education by inviting them to enter into the process of thinking

critically about their reality (cited in Shön, 2010, p. 2).

Charles Dickens cited in Darling and Nordendo (2003) ridicules an approach to education in which the highest importance is attached to the direct transmission of information and where the value of imagination is deliberately downgraded. Knowledge (facts) is here valued for its utility. But what Dickens is pointing to is a broader view in which rich experience should be valued not just for its own sake but for its ability to prepare us for the rest of life.

What makes Dickens as a progressivist figure is that he valued the concept of experience. Thus, literature can act as a tool to immediate personal growth by taking the readers' literary experience at the point of departure. Kolb (1987) cited in Nunan (1999) said experiential learning builds a bridge from the known to the new by taking the learners' experience as the point of departure. Along the same line, Kohonen (1992) says that experiential learning: facilitate personal growth; helps learners to adapt to social change; takes into account differences in learning ability is responsive to learners' needs and practical pedagogical considerations.

Elsewhere, Kohonen (1992) experiential learning provides a rich source of interactive practices through imaginative activities. It goes without saying that this type of learning is in effect is one of the fruit of reading literature. Put similarly, another power of literature in enhancing the power of thinking is that it provides a rich source of imaginative input that helps students develop their innovative power. As Shelley (1989) puts it literature is the expression of imagination (cited in Conway, 1996, p. 3). Elsewhere, Cownway (1996) asserts, imagination forms bridges between existence and perception, between perception and expression. Also, regarding the power of imagination Albert Einstein, talking from his own experiences and drawing on those of others, concluded, "imagination is more important than knowledge" (cited in Leong, 2004, p. 1).

Students' power of imagination will certainly get improved when students are permitted to talk from their vantage points, while scaffold by teachers either linguistically or non-linguistically; therefore, assuming students' imagination to be developed simply by providing an inflexible, lateral relationship that is always directed by teachers has no sense. Regarding the importance of imagination in developing critical thinking, Conway (1996), maintains, "imagination is a natural part of the structure of the mind which must be trained or attuned to appreciate the greatness of art, to develop a meaningful standard of taste" (p. 2). As to Frye (1964), "It is clear that the end of literary teaching is not simply the admiration of literature; it's something more like the transfer of imaginative energy from literature to the students" (p. 531).

\section{A Suggested tool}

One way that teachers can facilitate the process of thinking is to appeal to Socratic questioning. By employing Socratic questioning in literature the readers can pursue thoughts in many directions and for many purposes, including: to explore complex ideas, to get to the truth of things, to open up issues and problems, etc. The art of Socratic questioning is intimately connected with Critical Thinking because the art of questioning is important to excellence of thought. What the word "Socratic" adds to the art of questioning is systematicity and depth in assessing the facts and opinions.

Both Critical Thinking and Socratic questioning share a common end. Both are in their pursuit of meaning and truth. In a nutshell, in teaching, teachers can use Socratic questioning for at least two purposes: (1) to help students begin to distinguish what they know or what they do not know; (2) to foster students' abilities to ask Socratic questions, to help students acquire the powerful tools of Socratic dialogue, so that they can use these tools in everyday life (Paul \& Elder, 2006). To this end, teachers can model the questioning strategies they want students to emulate and employ. In fact, Critical Thinking through the employment of Socratic questioning teaches students to dig beneath the surface of ideas. It teaches us the value of developing questioning minds in cultivating deep learning. 
In the same line, some of the Socratic questions that if cautiously employed will certainly help students develop their Critical Thinking are as follows: (1) getting students to clarify their thinking e.g., 'Why do you say that?'; (2) challenging students about assumptions, e.g., 'Is this always the case?'; (3) alternative viewpoints and perspectives, e.g., 'What is the counter argument for?', and the most meticulous one (4) question the question e.g., 'Why do you think that I asked that question.

\section{Conclusion}

Claiming that literature should be excluded from EFL/ESL curriculum, simply due to its structural complexity, remote cultural perspective (Topping, 1968), is not well persuasive. In fact, its cultural load, structural complexity and non-normative use of language as claimed, is exactly what can be employed to enrich language teaching and learning experiences, and enhance critical thinking. Moreover, as Zoreda and Vivaldo-Lima (2008) outlines literature certainly (1) helps language teachers foster their own cultural, linguistic and interpretive skills; (2) involves students overcome negative attitudes, if any, toward the target culture; and (3) introduces variety into the language classroom (cited in Bagherkazemi \& Alemi, 2010, p. 3).

Along these lines, Collie \& Slater (1987) cited in Shön (2010) found that "extensive reading increases a learner's receptive vocabulary and facilitates transfer to more active form of knowledge" (p. 1). These all are accessible provided that students are interested in reading and the text provides no difficulty for them either linguistic or cultural. Still, it goes without saying that, we should consider the other side of the coin if one reads a story without any difficulty, the story for him will not have any value as a resource for developing language.

However, it is worth mentioning developing critical thinking through reading literature in societies which the concept of critical is considered rude to teachers is hardly imaginable. As Yan (2006) reports; in China, for instance, both teachers and students have been greatly influenced by the cultural tradition, mostly by the Confucian tradition. The relationship between teacher and student is much more hierarchical. Within the Confucian tradition, teachers play the role of authority and dominate the class mainly through their talk, while students are passive receivers and more inclined to believe what the teachers say instead of trying to work out their own answers or to solve the problems by them. As to Shön (2010), in such societies being critical of teachers or their lessons is regarded as rude behavior. Nevertheless, what the writers claim is that even in such situated environments where students are forced to pursue a predetermined philosophy, there is a chance to shape their own identity through critical thinking and literature reading. Not to mention, reading literature and the critical discussion that ensues from it will also "help students gain a multi-faced view of the world and themselves" (Shön, 2010).

\section{References:}

Bagherkazemi, M., \& Alemi, M. (2010). Literature in the EFL/ESL classroom: Consensus and controversy. Linguistic and Literary Broad Research and Innovation, 1(1), 1-12.

Bradford, A. (1968). Reading literature and learning a second language. Language Learning, 18(3/4), 199-210.

Chastain, K. (1988). Developing language skills: Theory and practice. London: Harcourt Brace Jovanovich.

Conway, S. (1996). Imagination and literature. Retrieved in May 15, 2012, from http://www.subverbis.com/essays/imagination.rtf

Darling, J., \& Nordendo, S. E. (2003). Progressivism. In N. Blake, P. Sweyers, S. Richard, \& P. Standish, The philosophy of education (pp. 288-308). Oxford: Blackwell Publishing.

Ellison, M. (2010). Make them think: Using literature in the primary English language classroom to develop critical thinking skills. E-F@BULACOES, 7, 21-31.

Facione, P. A., Sanchez, C. A., Facione, N. C., \& Gainen, J. (1995). The disposition toward critical thinking. Journal of General Education, 44(1), 1-25.

Frye, N. (1964). The educational imagination. Indiana: Indiana University Press.

Honeyfield, J. (1977). Simplification. TESOL Quarterly, 11(4), 431-440. <http://dx.doi.org/10.2307/3585739> 
Khatib, M. \& Shakouri, N.

Hume, D. (1989). Of the standard taste. In D. H. Ritcher (Ed), The critical tradition. New York: Martin's Press.

Khatib, M., Rezaei, S., \& Derakhshan, A. (2011). Literature in EFL/ESL classroom. English Language Teaching, 4 (1), 201-208.

Kohonen, V. (1992). Experiential language learning: second language learning as cooperative learner education. In D. Nunan (ed.), Collaborative language learning and teaching (pp. 14-39). Cambridge: Cambridge University Press.

Leong, S. S. L. (2004). The power of imagination: Its role in students' participation in creating knowledge. Paper presented at Simon Fraser University, Vancouver, Canada.

McKay, S. (1982). Literature in the ESL classroom. TESOL QUARTERLY, 16(4), 529-536. $<$ http://dx.doi.org/10.2307/3586470>

Monchinski, T. (2008). Critical pedagogy and the everyday classroom. Boston: Springer.

Paul, R. (1983). An agenda item for the informal logic/critical thinking movement. Informal Logic Newsletter, $5(2), 23$.

Paul, R., \& Elder, L. (2006). The thinker's guide to the art of Socratic questioning. Dillon Beach, CA: Foundation for Critical Thinking.

Reece, G. (2002). Critical thinking and transferability: A review of literature. Retrieved July 15, 2011, from http:// www.library.american.edu/.../critical_thinking.pdf

Shön, Y. (2010). Making students critical readers in a Korean middle school reading class. Interfaces, 4(1).

Spack, R. (1985). Literature, reading, writing, and ESL: Bridging the gaps. TESOL Quarterly, 19(4), 703-725. $<\underline{\text { http://dx.doi.org/10.2307/3586672> }}$

Strevens, P. (2003). Applied linguistics: An overview introduction to applied Linguistics. In W. Grabe \& R. B. Kaplan (Eds.), Introduction to applied linguistics (pp. 13-31). London: Addison-Wesley Publishing Company, Inc.

Topping, D. M. (1968). Linguistics or Literature: an approach to Language. TESOL Quarterly, 2(2), 95-100. $<$ http://dx.doi.org/10.2307/3586085>

Tung, C. A., \& Chang, S. Y. (2009). Developing critical thinking through literature reading. Feng Chia Journal of Humanities and Social Sciences, 19, 287-317.

Wertsch, J. V. (2002). Computer mediation, PBL, and dialogicality. Distance Education, 23(1), 105-108. $<$ http://dx.doi.org/10.1080/01587910220124008>

Williams, M., \& Burden, R. L. (1997). Psychology for language teacher: A social constructivist approach. Cambridge: Cambridge University Press.

Wilson, K. (2007). Facilitator talk in EAP reading classes. ELT Journal, 62(4), 366-374. $<$ http://dx.doi.org/10.1093/elt/ccm067>

Zoller, U., Ben-Chaim, D., \& Ron, S. (2000). The disposition toward critical thinking of high school and university science students: An inter-intra Israeli-Italian study. International Journal of Science Education, 22(6), 571-582. <http://dx.doi.org/10.1080/095006900289679> 